\title{
Isolation and expansion of muscle precursor cells from human skeletal muscle biopsies
}

Chiara Franzin ${ }^{1, *}$, Martina Piccoli ${ }^{1}$, Luca Urbani $^{2}$, Carlo Biz ${ }^{3}$, Piergiorgio Gamba ${ }^{4}$, Paolo De Coppi $^{2}$, Michela Pozzobon ${ }^{1, *}$

${ }^{1}$ Stem cells and Regenerative Medicine Laboratory, Fondazione Istituto di Ricerca Pediatrica Città della Speranza, Padova, Italy

${ }^{2}$ Stem Cells \& Regenerative Medicine Section, Developmental Biology \& Cancer Programme, UCL Institute of Child Health and Great Ormond Street Hospital, London, United Kingdom

${ }^{3}$ Orthopedic Clinic, Department of Surgery, Oncology and Gastroenterology DiSCOG, University of Padova, Padova, Italy

${ }^{4}$ Pediatric Surgery Unit, Woman and Children's Health Department, University of Padova, Padova, Italy.

* To whom correspondence should be addressed:

c.franzin@irpcds.org

m.pozzobon@irpcds.org

Stem Cells and Regenerative Medicine Lab

Istituto di Ricerca Pediatrica Città della Speranza

Corso Stati Uniti 4, 35127 Padova, Italy

Running head: Isolation of human muscle precursor cells 


\begin{abstract}
One of the major issues concerning human skeletal muscle progenitor cells is represented by the efficient isolation and in vitro expansion of cells retaining the ability to proliferate, migrate and differentiate once transplanted. Here we describe a method i) effective in obtaining human muscle precursor cells both from fresh and frozen biopsies coming from different muscles, ii) selective to yield cells uniformly positive for CD56 and negative for CD34 without FACS sorting, iii) reliable in maintaining proliferative and in vitro differentiative capacity up to passage 10 .
\end{abstract}

Key words: human muscle precursor cells, skeletal muscle biopsy, CD56, enzymatic digestion, human muscle cell primary culture.

\title{
1. INTRODUCTION
}

Two main approaches are currently employed for the obtainment of myogenic precursor cells, namely single fiber isolation, firstly described by Rosenblatt and colleagues [1] and applied also for human samples [2], and whole muscle enzymatic digestion with different adaptations $[3,4]$. The first method allows to get a virtually pure population of activate satellite cells but is a quite complex procedure, starting from the muscle collection which has to provide myofibers preserved in their length, whereas the second one is more simple and fast but yields a mixed cell population and usually need further passages such as preplating or fluorescence-activated cell sorting $[5,6]$. In terms of surface antigen expression, different proteins have been investigate to better define the precursor cells in human muscle, however so far the literature is quite unanimous in identifying the cells restricted to a myogenic fate in the $\mathrm{CD}^{+} 6^{+} \mathrm{CD} 34^{-}$population $[7,8]$.

Here we described a protocol to efficiently isolate and expand in culture human muscle precursor cells from different skeletal muscles through a whole muscle digestion method without the need of further cell processing. This is possible following the combination of (i) careful biopsy collection and cleaning, (ii) double enzymatic digestion, (iii) defined medium composition and appropriate 
plastic ware. This method allows obtaining homogeneous $\mathrm{CD}^{+} 6^{+} \mathrm{CD} 34^{-}$cell population that maintain proliferative and in vitro differentiative capacity up to passage 10. Moreover, although other improvements mainly regarding culture conditions are needed in the perspective of a future possible clinical application, we defined a freezing procedure that does not affect cell isolation and characteristics.

\section{MATERIALS}

\subsection{Culture media and plastic ware}

1. Prepare the Collagenase I $0.2 \%$ (w/v) solution: weigh $200 \mathrm{mg}$ of lyophilized Collagenase from Clostridium histolyticum for general use, Type I (Sigma Aldrich) and resuspend with 2 mL of DMEM 1X $1 \mathrm{~g} / \mathrm{L}$ glucose (+) L-Glutamine (+) Pyruvate (GIBCO, Thermo Fisher Scientific), then add $98 \mathrm{~mL}$ of DMEM. Filter the solution through a $0.22 \mu \mathrm{m}$ filter and stock single-use aliquots at $-20^{\circ} \mathrm{C}$.

2. Trypsin $0.05 \%$ with EDTA and Phenol Red (GIBCO, Thermo Fisher Scientific).

3. Red blood cell lysis buffer: Auto Lyse Plus (Biosource).

4. Washing medium: DMEM $1 \mathrm{X} 1 \mathrm{~g} / \mathrm{L}$ glucose (+) L-Glutamine (+) Pyruvate containing $20 \%$ fetal bovine serum (FBS) (GIBCO, Thermo Fisher Scientific) and 1\% Penicillin Streptomicin (pen/strep) (GIBCO, Thermo Fisher Scientific).

5. Proliferation medium: DMEM $1 \mathrm{X} 1 \mathrm{~g} / \mathrm{L}$ glucose (+) L-Glutamine (+) Pyruvate containing $20 \% \mathrm{FBS}, 10^{-6} \mathrm{M}$ dexamethasone (Sigma Aldrich), $10 \mathrm{ng} / \mathrm{mL}$ recombinant mouse FGF basic protein (R\&D Systems), $10 \mu \mathrm{g} / \mathrm{mL}$ insulin (Insuman Rapid 100UI/mL, Sanofi Aventis) and $1 \%$ pen/strep.

6. Differentiation medium: MEM Alpha (1X), (+) L-Glutamine, (+) Ribonucleosides, $(+)$ Deoxyribonucleosides, (-) Ascorbic Acid (GIBCO, Thermo Fisher Scientific) containing 2\% horse serum (GIBCO, Thermo Fisher Scientific), $10 \mu \mathrm{g} / \mathrm{mL}$ insulin and 1\% pen/strep. 
7. Freezing medium: 70\% FBS, 10\% DMEM 1X $4.5 \mathrm{~g} / \mathrm{L}$ glucose (+) L-Glutamine (+) Pyruvate (GIBCO, Thermo Fisher Scientific), 20\% dimethyl sulfoxide.

8. Non-Tissue Culture Treated (NTC) Plate, polystyrene, flat bottom: 96-well, 24-well and 6well plates (Falcon, Corning). Use these plates for cell expansion and proliferating cell characterization.

9. Non-Tissue Culture (NTC) polystyrene Petri dishes, $100 \times 20 \mathrm{~mm}$ and $150 \times 25 \mathrm{~mm}$ (Falcon, Corning). Use these plates for cell expansion.

10. Tissue Culture Treated (TC) Plate, polystyrene, flat bottom: 24-well plates (Falcon, Corning). Use these plates for myogenic differentiation.

\subsection{Flow cytometry analysis}

1. Tubes or other supports suitable for your cytometer.

2. Antibodies anti-human antigens: CD34-FITC clone 581, CD56-PE clone B159, 7aminoactinomycin D (7AAD) (all from BD Pharmigen). Isotype controls: mouse IgG1 FITC (IOTest Immunotech), PE mouse anti-human Ig k (BD Pharmigen).

\subsection{Immunofluorescence analysis}

1. Routine reagents: $4 \%$ paraformaldehyde (PFA) for fixation, $0.5 \%$ Triton-X100 in phosphate-buffered saline (PBS) for permeabilization, 10\% horse serum in PBS for saturation, $1 \%$ bovine serum albumin (BSA) in PBS for antibodies dilution, 4',6-diamidino2-phenylindole (DAPI) fluorescence mounting medium for nuclei counterstaining.

2. Proliferating cell characterization. Primary antibodies: monoclonal rabbit IgG anti-human Ki-67 clone SP6 (Novusbio), monoclonal mouse $\operatorname{IgG}_{1}$ anti-human PAX7 clone PAX7 (R\&D systems), polyclonal rabbit IgG anti-human MYOD clone M318 (Santa Cruz Biotechnology), polyclonal rabbit IgG anti-human MYF5 clone C20 (Santa Cruz Biotechnology). Secondary antibodies: chicken anti-rabbit IgG $(\mathrm{H}+\mathrm{L})$ Alexa Fluor® 594 conjugate (Thermo Fisher Scientific), goat anti-mouse IgG (H+L) Alexa Fluor® 594 conjugate (Thermo Fisher Scientific). 
3. Differentiated cell characterization. Primary antibody: monoclonal mouse $\operatorname{IgG}_{2 \mathrm{~B}}$ anti-human Myosin Heavy Chain clone MF20 (R\&D systems). Secondary Antibody: goat anti-mouse IgG (H+L) Alexa Fluor® 594 conjugate (Thermo Fisher Scientific).

\section{METHODS}

\subsection{Cell isolation}

1. Carry the muscle biopsy (see Note 1, Fig. 1 and Fig. 2) in sterile saline from operating theatre to the laboratory cell processing room (see Note 2).

2. Transfer the sample on a Petri dish using disposable sterile plastic pincers and quickly rinse it with Betadine ${ }^{\circledR}$ or similar products and PBS.

3. Transfer the sample in a clean Petri dish and carefully remove visible vasculature, connective tissue and potential adipose tissue (see Note 3 ).

4. Divide the muscle in pieces weighting up to $500 \mathrm{mg}$ (see Note 4) and treat every piece separately.

5. Mince the sample in very small pieces $\left(1-2 \mathrm{~mm}^{3}\right)$ using two disposable sterile scalpels.

6. Cover minced sample with $3 \mathrm{~mL}$ of $0.2 \%$ (w/v) Collagenase I in a well of 6-well plate and incubate for $90 \mathrm{~min}$ at $37^{\circ} \mathrm{C}$.

7. Transfer the digestion product in a $15 \mathrm{~mL}$ conical centrifuge tube, add $10 \mathrm{~mL}$ of washing medium and homogenate with serological pipette, then centrifuge at $300 \mathrm{x} g$ for $10 \mathrm{~min}$.

8. Take out the supernatant and resuspend the pellet with $2 \mathrm{~mL}$ of $0.05 \%$ Trypsin-EDTA, transfer in a well of 6-well plate and incubate for $60 \mathrm{~min}$ at $37^{\circ} \mathrm{C}$.

9. Transfer the digestion product in a $15 \mathrm{~mL}$ conical centrifuge tube, add $10 \mathrm{~mL}$ of washing medium and homogenate with serological pipette, then filter twice the cell suspension first through $70 \mu \mathrm{m}$ and then $40 \mu \mathrm{m}$ cell strainers. Centrifuge at $300 \mathrm{x} g$ for $10 \mathrm{~min}$.

10. Resuspend the pellet in $3 \mathrm{~mL}$ red blood cell lysis buffer for $5 \mathrm{~min}$, add $10 \mathrm{~mL}$ of washing medium and centrifuge at $300 \mathrm{x} g$ for $10 \mathrm{~min}$. 
11. Resuspend the pellet in $2 \mathrm{~mL}$ of proliferation medium and seed cells in a well of 6-well NTC plate.

12. Refresh proliferation medium after 48-72 hours (see Note 5). Usually attached cells appear after 5-7 days from enzymatic digestion (see Note 6).

\subsection{Sample freezing}

1. Transfer minced sample obtained at step 5 of section 3.1 in a $2 \mathrm{~mL}$ cryovial and add $1 \mathrm{~mL}$ of freezing medium.

2. Proceed with slow cooling protocol as for cell samples and store in liquid nitrogen (see Note 7).

\subsection{Sample thawing}

1. Take out sample from liquid nitrogen and thaw in water bath at $37^{\circ} \mathrm{C}$.

2. Transfer sample in a $15 \mathrm{~mL}$ conical centrifuge tube, add $10 \mathrm{~mL}$ of washing medium and centrifuge at $300 \mathrm{x} g$ for $10 \mathrm{~min}$.

3. Proceed with step 6 of section 3.1.

\subsection{Cell expansion}

1. Take out the medium from the well or dish and wash twice with PBS. Add the appropriate volume of $0.05 \%$ Trypsin-EDTA (300 $\mu \mathrm{L}$ for wells of 6-well plate, $1 \mathrm{~mL}$ for 100 x $20 \mathrm{~mm}$ dishes, $2 \mathrm{~mL}$ for $150 \times 25 \mathrm{~mm}$ dishes) and incubate for $5-10 \mathrm{~min}$ at $37^{\circ} \mathrm{C}$.

2. Add washing medium, collect detached cells and centrifuge at 300 x $g$ for $10 \mathrm{~min}$. Remove the supernatant, resuspend cell pellet in proliferation medium and seed cells on a suitable NTC well or dish. Usually around $1 \times 10^{5}$ cells in a $100 \times 20 \mathrm{~mm}$ dish and $2.5 \times 10^{5}$ cells in a $150 \times 25 \mathrm{~mm}$ dish are seeded. We recommend never exceeding the $60-70 \%$ of confluence. In our experience cells maintain unaltered characteristics up to passage 10.

\subsection{Cell characterization}

1. Doubling time analysis (Fig. 3A): seed $1 \times 10^{4}$ cells for each well of 24-well NTC plate in proliferation medium, after $48 \mathrm{~h}$ detach cells by trypsin treatment and proceed with 
counting. Consider at least three wells separately. Calculate the doubling time (g) using the following equation $\mathrm{g}=48 \mathrm{hx}\left[\log 2 / \log \left(\mathrm{N}_{48 \mathrm{~h}} / \mathrm{N}_{0}\right)\right]$ in which $\mathrm{g}$ is the generation (or doubling) time during the logarithmic phase of the growth curve, $\mathrm{N}_{48 \mathrm{~h}}$ is the cell number at $48 \mathrm{~h}$ after seeding and $\mathrm{N}_{0}$ is the cell number at time 0 [9].

2. Flow cytometry analysis (Fig. 3B): detach cells by trypsin treatment and proceed with incubation using antibodies described in the Materials 2.2 section. Usually we observe more than $90 \%$ of CD56 positive cells and no cells positive for CD34.

3. Immunofluorescence analysis of proliferating cells (Fig. 3C-D): seed $5 \times 10^{3}$ cells for each well of 96-well NTC plate in proliferation medium, after $48 \mathrm{~h}$ take out the culture medium, wash twice with PBS and fix cells by incubation with $4 \%$ PFA at $4{ }^{\circ} \mathrm{C}$ for $10 \mathrm{~min}$. Proceed with the immunostaining protocol using the antibodies described in the Materials $\mathbf{2 . 3}$ section paragraph 2.

4. Myogenic differentiation and myogenic index evaluation (Fig. 3E): seed $1.5 \times 10^{4}$ cells for each well of 24-well TC plate in proliferation medium and let cells proliferate for $48 \mathrm{~h}$, then take out the medium and add differentiation medium. After $48 \mathrm{~h}$ refresh differentiation medium and after other $48 \mathrm{~h}$ take out the medium, wash twice with PBS and fix cells by incubation with $4 \%$ PFA at $4{ }^{\circ} \mathrm{C}$ for $10 \mathrm{~min}$. Proceed with the immunostaining protocol using the antibodies described in the Materials 2.3 section paragraph 3. Calculate the myogenic index defined as the number of nuclei residing in cells containing three or more nuclei divided by the total number of nuclei [10]. Consider at least 5 fields at $20 \mathrm{X}$ magnification for each sample.

\section{NOTES}

1. We experienced efficient isolation and expansion of muscle precursor cells starting from biopsies obtained from different adult skeletal muscle listed in Fig. 1. We also applied our 
method to pediatric abdominal muscle biopsies and derived muscle precursor cells with similar features to those observed in cells of adult origin (described in Fig. 3).

2. If it is not possible to process the biopsy immediately after surgery it can be maintained in sterile saline at $4{ }^{\circ} \mathrm{C}$ not longer than 24 hours.

3. We considered biopsies from adult healthy subjects aged from 25 to 60 years undergoing scheduled orthopedic operations or surgery after trauma, with muscle being virtually free of ectopic adipose tissue deposition that is instead present during aging or in some pathological condition [11].

4. For samples weighting less than $200 \mathrm{mg}$ adjust reagent volumes and plastic ware as following:

- $1.5 \mathrm{~mL}$ of $0.2 \%$ Collagenase I in a well of $24-w e l l$ plate (step 6 of section 3.1 )

- $1 \mathrm{~mL}$ of $0.05 \%$ Trypsin-EDTA in a well of 24-well plate (step 8 of section 3.1 )

- avoid incubation with red blood cells lysis buffer (step 10 of section 3.1)

- seed cells in $1 \mathrm{~mL}$ of proliferation medium in a well of 24-well NTC plate (step 11 of section 3.1)

In case of small samples attached cells could appear slightly later (7-10 days).

5. Despite of washing and filtering procedures it is possible to still observe cell and fiber debris at this stage, we thus recommend taking out medium and washing cells with PBS or washing medium before adding fresh proliferation medium.

6. If attached cells appear before 5 days, it is possible that fibroblasts overcame the proliferation of myogenic cells. This may occur despite the careful removal of connective tissue from biopsies and an accurate muscle sample collection during surgery can help in avoiding this inconvenience. Although the large and granular appearance of fibroblasts is easily distinguishable from the elongated and thin shape of myogenic cells, we recommend performing flow cytometry analysis at earlier passage as possible to evaluate the percentage of CD56 positive cells. 
7. In our experience there are not differences between freshly processed and frozen/thawed biopsies, apart a possible delay in the appearance of attached cells.

8. Both adult and pediatric biopsies were taken after approval by local ethical committee and informed consent acceptance by patients (Prot N. 2682P and 3030P, Azienda Ospedaliera di Padova).

\section{ACKNOWLEDGEMENT}

This work has been funded by Fondazione Istituto di Ricerca Città della Speranza (Grant number 12/01) and CARIPARO-IRP Ricerca Pediatrica Program (Grant number 13/04). Luca Urbani and Paolo De Coppi are supported by GOSH and NIHR (RP-2014-04-046).

\section{FIGURE LEGENDS}

Fig. 1 Muscle sources. Biopsies were obtained from different skeletal muscles, as highlighted in pink in the illustration; the numbers of samples analyzed for each muscle are listed in the table.

Fig. 2 Method outline. After washing and removal of non-muscle tissue (1) samples are directly subject to enzymatic digestion (2.1) or frozen for later use (2.2). Isolated cells are cultured for several passages (3) and characterized in terms of surface antigen expression, proliferation, myogenic marker expression and myogenic index (4).

Fig. 3 Cell characterization. A) Representative image of cell appearance in culture at phase contrast microscope $($ scale bar $=100 \mu \mathrm{m})$ and bar graph of doubling time calculated at different passages. B) Representative dot-plot of expanded cells (passage 5) analyzed for the expression of CD56 and CD34 and bar graph of CD56 expression at different passages. C) Representative pictures of Ki67 and myogenic markers expression (passage 5) $($ scale bar $=100 \mu \mathrm{m})$. D) Percentage of cells positive for Ki67 and myogenic markers at different passages (at least 5 fields for each independent experiment). E) Representative picture of myosin heavy chain staining (passage 5) 
$(\mathrm{scale}$ bar $=100 \mu \mathrm{m})$ and myogenic index calculation at different passages (at least 5 fields for each independent experiment).

\section{REFERENCES}

1. Rosenblatt JD, Lunt AI, Parry DJ, Partridge TA (1995) Culturing satellite cells from living single muscle fiber explants. In Vitro Cell Dev Biol Anim 31 (10):773-779. doi:10.1007/BF02634119

2. De Coppi P, Milan G, Scarda A, Boldrin L, Centobene C, Piccoli M, Pozzobon M, Pilon C, Pagano C, Gamba P, Vettor R (2006) Rosiglitazone modifies the adipogenic potential of human muscle satellite cells. Diabetologia 49 (8):1962-1973. doi:10.1007/s00125-006-0304-6

3. Agley CC, Rowlerson AM, Velloso CP, Lazarus NR, Harridge SD (2013) Human skeletal muscle fibroblasts, but not myogenic cells, readily undergo adipogenic differentiation. J Cell Sci 126 (Pt 24):5610-5625. doi:jcs.132563 [pii]

$10.1242 / \mathrm{jcs} .132563$

4. Gaster M, Kristensen SR, Beck-Nielsen H, Schroder HD (2001) A cellular model system of differentiated human myotubes. APMIS 109 (11):735-744

5. Jankowski RJ, Haluszczak C, Trucco M, Huard J (2001) Flow cytometric characterization of myogenic cell populations obtained via the preplate technique: potential for rapid isolation of muscle-derived stem cells. Hum Gene Ther 12 (6):619-628. doi:10.1089/104303401300057306 6. Xu X, Wilschut KJ, Kouklis G, Tian H, Hesse R, Garland C, Sbitany H, Hansen S, Seth R, Knott PD, Hoffman WY, Pomerantz JH (2015) Human Satellite Cell Transplantation and Regeneration from Diverse Skeletal Muscles. Stem Cell Reports 5 (3):419-434. doi:S2213-6711(15)00222-2 [pii] 10.1016/j.stemcr.2015.07.016

7. Bareja A, Holt JA, Luo G, Chang C, Lin J, Hinken AC, Freudenberg JM, Kraus WE, Evans WJ, Billin AN (2014) Human and mouse skeletal muscle stem cells: convergent and divergent mechanisms of myogenesis. PLoS One 9 (2):e90398. doi:10.1371/journal.pone.0090398 PONE-D-13-42782 [pii] 
8. Pisani DF, Dechesne CA, Sacconi S, Delplace S, Belmonte N, Cochet O, Clement N, Wdziekonski B, Villageois AP, Butori C, Bagnis C, Di Santo JP, Kurzenne JY, Desnuelle C, Dani C (2010) Isolation of a highly myogenic CD34-negative subset of human skeletal muscle cells free of adipogenic potential. Stem Cells 28 (4):753-764. doi:10.1002/stem.317

9. Scarda A, Franzin C, Milan G, Sanna M, Dal Pra C, Pagano C, Boldrin L, Piccoli M, Trevellin E, Granzotto M, Gamba P, Federspil G, De Coppi P, Vettor R (2010) Increased adipogenic conversion of muscle satellite cells in obese Zucker rats. Int J Obes (Lond) 34 (8):1319-1327. doi:ijo201047 [pii] 10.1038/ijo.2010.47

10. van der Velden JL, Schols AM, Willems J, Kelders MC, Langen RC (2008) Glycogen synthase kinase 3 suppresses myogenic differentiation through negative regulation of NFATc3. J Biol Chem 283 (1):358-366. doi:M707812200 [pii]

10.1074/jbc.M707812200

11. Vettor R, Milan G, Franzin C, Sanna M, De Coppi P, Rizzuto R, Federspil G (2009) The origin of intermuscular adipose tissue and its pathophysiological implications. Am J Physiol Endocrinol Metab 297 (5):E987-998. doi:00229.2009 [pii]

10.1152/ajpendo.00229.2009 


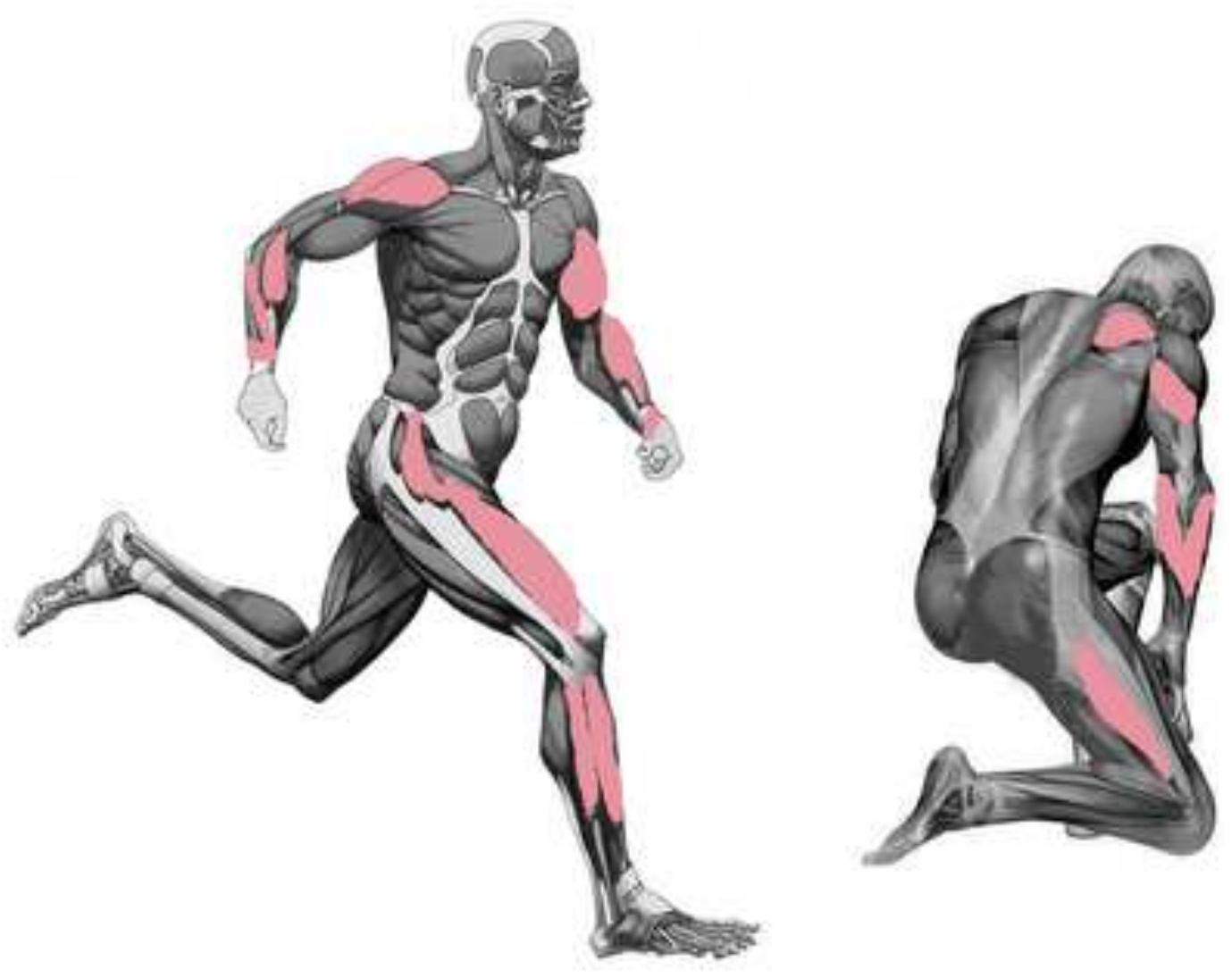

\section{Muscle type}

\section{Biopsies Number}

Biceps

Deltoid

Extensor forearm

Flexor carpi

Flexor longus pollicis

Flexor hallucis longus

Peroneus

Pronator teres

Quadriceps rectus femoralis

Sovraspinatus muscle

Tibialis

Triceps

Vastus lateralis

2

3

2

2

1

3

14

2

3

3

4

1

2 

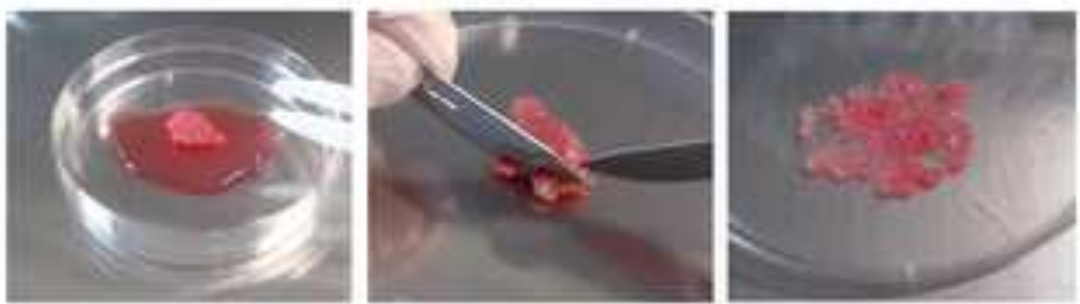

1) Sample preparation

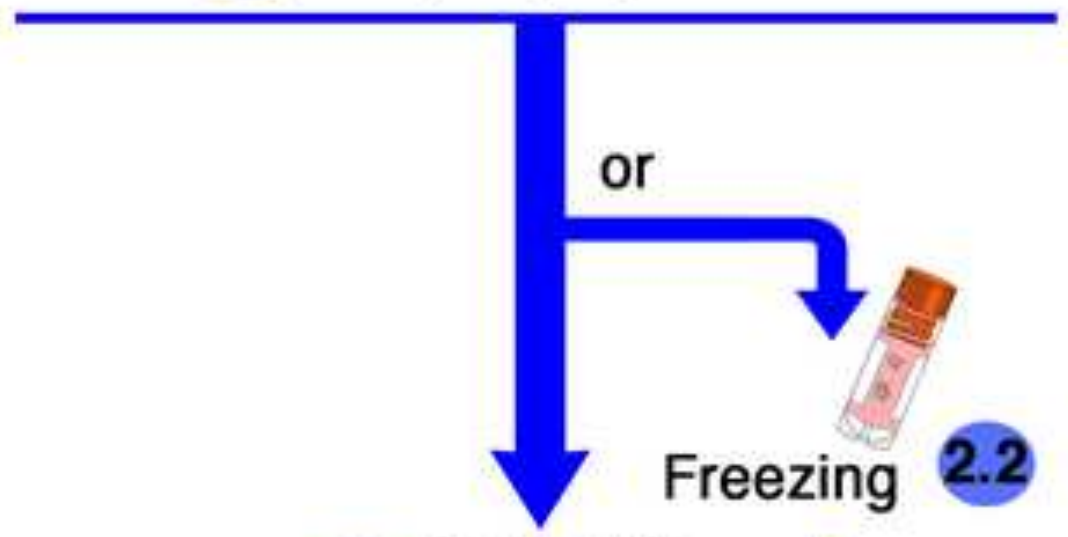

2.1 Enzimatic digestion

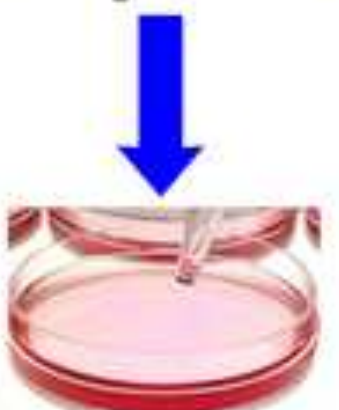

$3 \mathrm{hMPC}$ in vitro expansion

4 Analysis
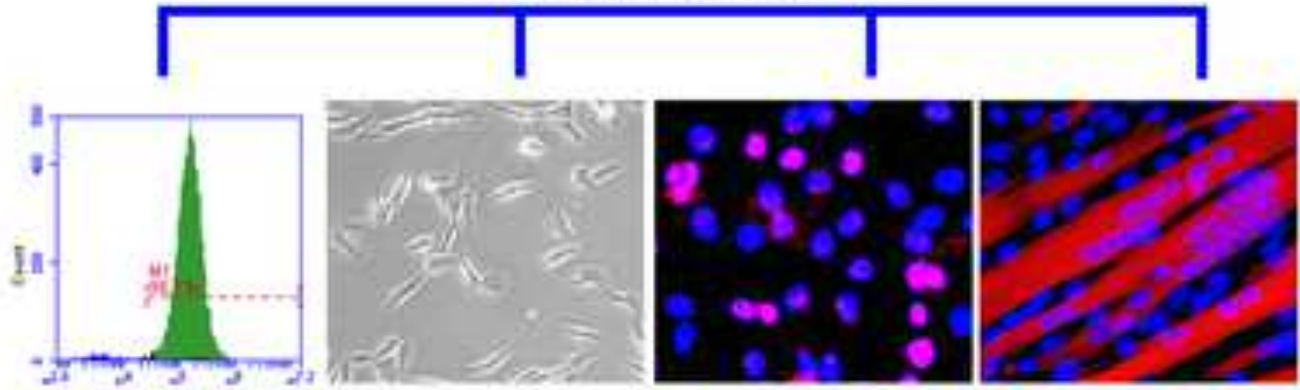

Surface

Cell

Myogenic Myogenic antigens proliferation markers index 

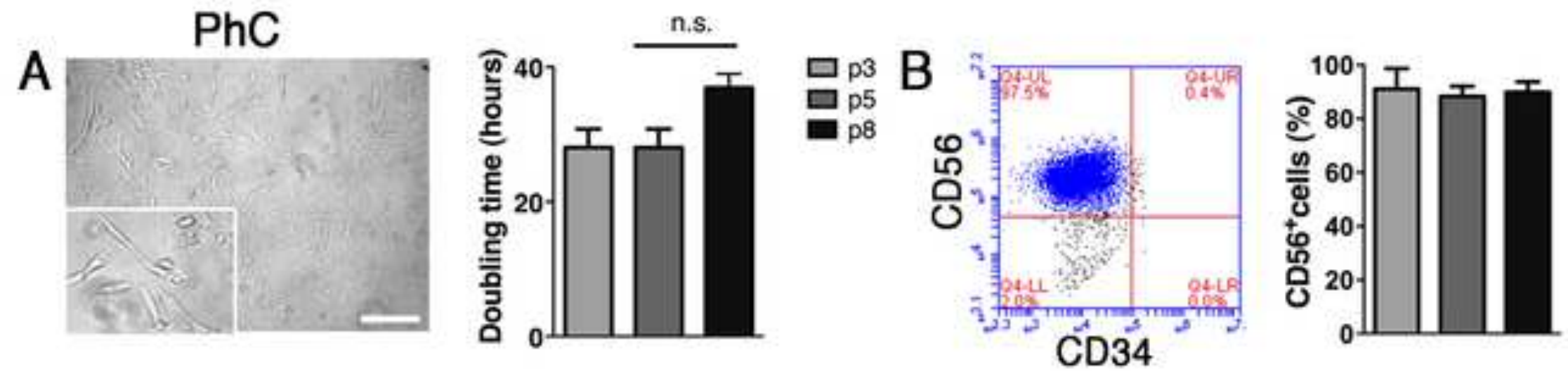

C
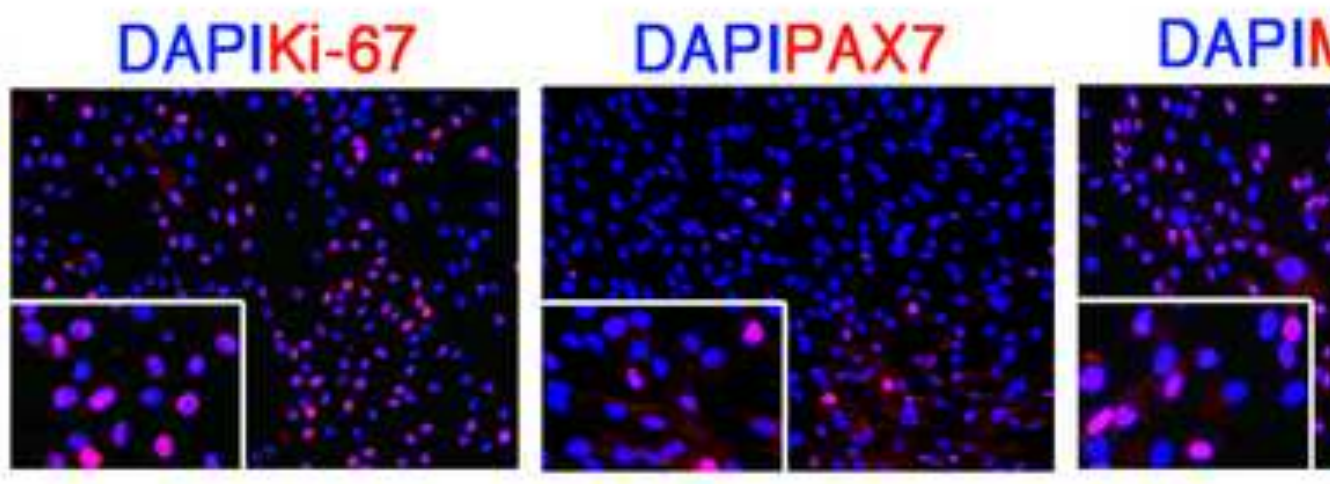

D

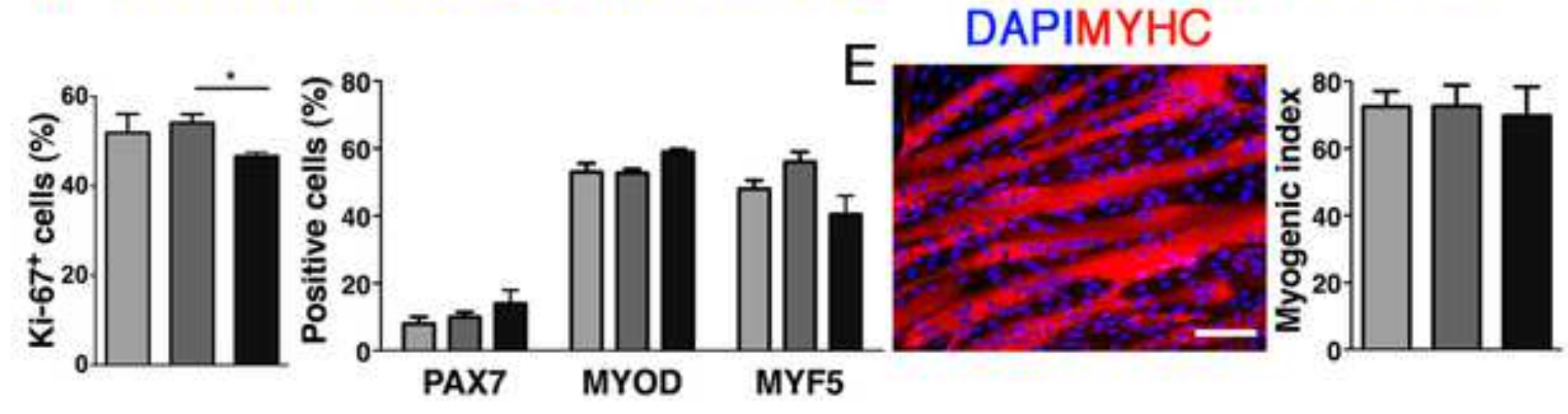

